\title{
Examining the Anatomy of a Screencast: Uncovering Common Elements and Instructional Strategies
}

\author{
William Sugar, Abbie Brown, and Kenneth Luterbach \\ East Carolina University, USA
}

\begin{abstract}
The researchers engaged in cooperative inquiry in order to explore screencasts as online instructional tools. In total, each researcher analyzed 37 screencasts, which provided over two hours of instruction. The content area of these screencasts concentrated on teaching specific computing procedures (e.g., how to install web server software or how to add a table in a word processor). The researchers analyzed their own self-produced screencasts as well as those that were professionally produced. Analyses of the screencasts led the researchers to discover common structural components (i.e., bumpers, screen movement, and narration) and common instructional strategies (i.e., provide overview, describe procedure, present concept, focus attention, and elaborate content). By synthesizing the common structure and common instructional strategies, the researchers offer a framework for considering the role of screencasts as online instructional tools. To introduce a practical application of the framework, the researchers created a screencasting checklist, which may be used by online instructors and instructional designers to develop and assess their own screencasts. This initial work invites additional research and development in order to refine the screencasting framework and checklist.
\end{abstract}

Keywords: Screencasting; screencasts; instructional media production; online learning; instructional strategies; online tutorials 
Instructional Design and Technology faculty who teach online courses face continual challenges in effectively disseminating information to students about instructional media production (e.g., creating a motion tween in Flash) and other relevant skills (e.g., how to install an Apache web server). In face-to-face courses, PowerPoint presentations (including question-and-answer periods), demonstrations in computer lab sessions, and similar instructional activities are used to present this information. However, these face-to-face instructional strategies do not effectively translate to asynchronous online learning environments. To address the instructional gap created by the loss of face-to-face interactions, we are examining the use of screencasting as a means of improving our online course instruction. As we faced the challenge of providing online, asynchronous instruction in our Instructional Design and Technology programs, we asked ourselves the following question: Can screencasting improve instruction in our online courses?

\section{What is a Screencast?}

Coined by Udell (2005), screencasting is a way to present "digitally recorded playback of computer screen output which often contains audio narration" and to visually demonstrate procedural information to students (e.g., inserting an image into an InDesign file). Also, the term screencast has been called "streaming desktop video captures," "online tutorials," and "screen captures” (Betty, 2008). In a screencast, the instructor records all of the necessary mouse clicks and corresponding screen activity to complete a designated task. The captured video can be accompanied with audio to create a multimedia presentation that clearly explains the actions (e.g., a series of mouse clicks), thoughts, and supporting details of the instructor (Peterson, 2007). One of the primary features of an instructional screencast is the direct capture of screen activity and images continuously. Audio can also be recorded simultaneously with the screen images.

While we are using screencasts with Instructional Design and Technology students, educators in other disciplines are also using screencasting for instructional purposes. Instructional screencasts and online video tutorials have been developed to teach a wide variety of topics, including objectoriented programming (Lee, Pradhan, \& Dalgarno, 2008), undergraduate student research (Jenkins-Brown, 2008), assistive technologies (Van Laarhoven et al., 2008), mathematical modeling (Ellington \& Hardin, 2008), nursing (Phillips \& Billings, 2007), and the Dewey Decimal Classification System (Peterson, 2007). The aim of these screencasts and video tutorials is to teach learners about a topic and to demonstrate specific actions associated with the particular content area.

\section{Instructional Benefits and Advantages of Screencasting}

There are definite benefits and advantages in using a screencast for instructional purposes. In their respective learning environments (e.g., home, office, coffee shop, etc.), learners can view a particular screencast at their own convenience and multiple times, if desired. By using a screencast, learners can see how to complete a particular procedure (e.g., how to insert a table in a word-processing file) and can observe what the actual screen looks like in completing the specific operation (Peterson, 2007). The inclusion of video-based instruction in online environments, such as screencasting, can have positive effects on student learning and can be pedagogically 
equivalent to their face-to-face instruction counterparts (Pang, 2009; Traphagan, Kucsera, \& Kishi, 2010). Hartsell and Yuen (2006) observed that online video-based instruction "brings courses alive by allowing online learners to use their visual and auditory senses to learn complex concepts and difficult procedures” (p. 31).

The combination of sound and images within a screencast enhances online learners' experiences compared to the more traditional text format and can be a powerful method of communicating content in an online setting. Mayer's (2001) theory of multimedia learning suggests that animated presentations that have a corresponding audio component, essentially moving picture and sound, provide a more effective learning experience than a more traditional alternative (e.g., a series of still pictures accompanied by descriptive text). This is in keeping with Paivio's (1986) dual coding theory, which posits that information processed through discrete input channels, one linguistically based channel and one non-linguistically based channel, has an additive effect that improves the learning experience.

In addition to presenting multiple media formats to learners, screencasts also model particular behaviors and operations. Theoretically, screencasting should have a positive effect on learning because it provides multiple input channels by presenting an expert performing and describing a task. Wouters, Paas, and van Merrienboer (2008) observed that the instructional methods of modeling and vicarious learning, in which experts perform problem-solving tasks for learners while explaining their actions, are a good fit with teaching task performance (specifically tasks that must be approached heuristically, something a bit more complex than following a simple algorithm) and complex cognitive skill mastery. Screencasting technology fits well with this instructional approach in that it presents digital video of the expert's actions for the learner to see while simultaneously presenting the expert's audio commentary on his/her actions. Conversely, Wouters et al. advise care in designing presentations that show performance of a complex task with visualizations and verbal explanations because there is danger of overloading the limited cognitive capacity of the learner. Wouters et al. cite the limitations explained by cognitive load theory (Sweller's [1988] theory, "that treats schemas, or combinations of elements, as the cognitive structures that make up an individual's knowledge base” [Soloman, n.d.]).

\section{Purpose of the Study}

While considering the current advantages and benefits of screencasting, the purpose of this study is to engage in disciplined inquiry in order to critically analyze the effects of instructional screencasts. Initially, we speculated that screencasting is a seemingly effective instructional method for our respective online instructional settings. Each of us (faculty member A, faculty member $\mathrm{B}$, and faculty member $\mathrm{C}$ ) received high teaching effectiveness scores (over 6.5 on a 7point scale) for our courses that included screencasts. Furthermore, our students have informally given us positive comments on the use of screencasts for instruction. However, we were unsure about the essential instructional and non-instructional components (e.g., strategies, methods) of an instructional screencast. The questions we are striving to answer through formal investigation are 
- What common instructional strategies are used in screencasts?

- How can we best understand the key components of an instructional screencast?

Engaging in this disciplined inquiry, we critically analyzed instructional screencasts and their role in online instruction. With this data, we expect to improve our own screencast production as well as to describe current practices for online instructors who are developing their own screencasts.

\section{Research Method}

We employed the cooperative inquiry approach (Heron, 1996; Reason \& Riley, 2008) in exploring the instructional components of our own screencasts and patterns of use that may be generalizable to other screencast development. The four stages of the cooperative inquiry approach may be summarized as

- Stage 1 - first reflection: During this stage, a group of researchers decides on the topics and methods of inquiry;

- Stage 2 - first action: During this stage, a group of researchers takes action based upon their first reflection and documents the outcomes of this action/inquiry;

- Stage 3 - second action: At this stage, a group of researchers may experience a new awareness and insight into the research topic;

- Stage 4 - second reflection: At this stage, a group of researchers reflect on their experiences, examine their findings, and refine their ideas for further research.

This interaction between the reflection and action stages continues until specific findings are established that respond to the initial research questions. All three authors were active research participants in this reflection/action process. In our collaboration, we made specific research decisions by consensus and each shared the results of our individual analysis of each screencast. This process enabled us to discover and articulate common elements of an instructional screencast.

\section{Independent Analyses of Screencasts}

We conducted two phases of reflection and action screencast analysis: examination of our own screencasts and examination of professionally produced screencasts. The content area of these screencasts concentrated on teaching specific computing procedures (e.g., how to install web server software or how to add a table in a word processor). 


\section{Analysis of our own screencasts.}

With the goal of identifying common structural elements and corresponding instructional strategies and methods, we examined 12 screencasts that we produced ourselves (approximately 62 minutes of total presentation time). These screencasts were developed for our own respective online courses. Each of these courses was delivered via our respective university's Blackboard site. Table 1 provides a brief description of each course.

\section{Table 1}

\section{Courses and Course Goals}

Faculty

\begin{tabular}{ll} 
member & Course \\
\hline $\begin{array}{l}\text { Faculty } \\
\text { member A }\end{array}$ & $\begin{array}{l}\text { Authoring Computer- } \\
\text { based Instruction }\end{array}$ \\
& \\
$\begin{array}{l}\text { Faculty } \\
\text { member A }\end{array}$ & $\begin{array}{l}\text { Multimedia Instructional } \\
\text { Product Development }\end{array}$
\end{tabular}

$\begin{array}{ll}\begin{array}{l}\text { Faculty } \\ \text { member B }\end{array} & \begin{array}{l}\text { Introductory } \\ \text { Instructional Design }\end{array} \\ \begin{array}{l}\text { Faculty } \\ \text { member B }\end{array} & \begin{array}{l}\text { Visual Design for } \\ \text { Educational Media }\end{array} \\ & \\ \begin{array}{l}\text { Faculty } \\ \text { member B }\end{array} & \text { Web-Based Instructional } \\ \end{array}$

Course goal

The overall goal of this graduate-level course is to give students hands-on experience with specific computer-based instruction authoring tools (mainly Flash and Dreamweaver) and working knowledge of computer-based instruction methodologies.

The overall goal of this graduate-level course is to give advanced instructional design students working knowledge and hands-on experience with the process of completing an actual multimedia instructional design project.

The overall goal of this graduate-level course is to introduce the concept of systematic instructional design. Course participants study the processes of instructional design.

The overall goal of this graduate-level course is to add to students' visual design skills in order to create better print-based, computer-based, and projected instructional media.

member B

Web-Based Instructional
Media

The overall goal of this graduate-level course is to give instructional design students a working knowledge of Web-based media production. Students produce podcasts, digital video, and HTML files, and they study the uses of online virtual reality and social networking.

$\begin{array}{ll}\text { Faculty } & \text { Introductory } \\ \text { member C } & \text { Instructional Design }\end{array}$

The overall goal of this graduate-level course is to introduce the concept of systematic instructional design. Course participants study the processes of instructional design.

Faculty Advanced Instructional One fundamental goal of this graduate-level 
member C Design

Faculty Introduction to member C Performance Technology course is to gain expertise in systematic instructional design processes. The second key goal is to challenge traditional notions of instructional design. Students design, develop, implement, evaluate, and refine instruction.

The overall goal of this graduate-level course is to introduce fundamental issues in Performance Technology. Students may develop an electronic performance support system or engage in an authentic performance improvement project.

Table 2 provides a description of each screencast and the corresponding instructional goal. The screencasts covered five topics: adding hyperlinks using Flash Actionscript 3, adding frame labels to a Flash file, performing basic Dreamweaver and InDesign operations, manipulating images using Photoshop and Paint, transferring files to a web server, and installing PHP and Apache server software.

Table 2

Screencasts and Instructional Goals

Faculty

member

Faculty Flash Components

member A

Faculty $\quad$ Frame Label

member A

Faculty Adding a Link - Basic

member A

Faculty

member A

Faculty

member B

Faculty

member B

Faculty

member B
Adding a Link - Advanced

Dreamweaver Basics Part 1

How to insert a frame label within a Flash CS3 file

Basic strategies on how to insert a link within a Flash CS3 file

Advanced strategies on how to insert a $\quad 5: 30$ link within a Flash CS3 file

How to create and save an HTML file. How to add and format text to an HTML file

Dreamweaver Basics Part 2 How to add graphics to HTML files Image Size and Resolution

How to use Photoshop to change an image's size and resolution
6:04

Screencast duration

6:11

11:50

12:01

5:48

4:27 


\begin{tabular}{lllc}
$\begin{array}{l}\text { Faculty } \\
\text { member B }\end{array}$ & InDesign Basics & How to navigate InDesign & $3: 18$ \\
$\begin{array}{l}\text { Faculty } \\
\text { Member C }\end{array}$ & Image Editing & How to resize an image in Paint & $1: 03$ \\
$\begin{array}{l}\text { Faculty } \\
\text { Member C }\end{array}$ & $\begin{array}{l}\text { Apache Web Server } \\
\text { Installation }\end{array}$ & How to install the apache web server & $2: 42$ \\
$\begin{array}{l}\text { Faculty } \\
\text { Member C }\end{array}$ & PHP Installation & How to install PHP & $4: 51$ \\
$\begin{array}{l}\text { Faculty } \\
\text { Member C }\end{array}$ & Electronic File Transfer & How to transfer files to a web server & $0: 43$ \\
\hline
\end{tabular}

We evaluated two screencasts from each faculty member for a total of six screencasts per iteration. We conducted this analysis twice, with the goal of refining our observations through a combination of repeated observation and discussion. At the end of each iteration, we reflected upon each screencast's structure, and we identified common components found among the six screencasts. As we watched each screencast independently, we made notes on its structure and the instructional methods used. We maintained a list of these components in an online Google Documents file for which each of us had author rights. At the end of each iteration, we refined our framework of screencast structural elements (see Figure 1).

\section{Analysis of professionally produced screencasts.}

After completing the first analysis phase of examining screencasts that we produced, we conducted a similar analysis of professionally produced screencasts. The professionally produced screencasts covered the following topics: creating a podcast using GarageBand, adding a table in a word processor (i.e., Pages), and writing conditional statements using Flash ActionScript 3. We purposefully selected these screencasts based on their task complexity; each was an activity similar to one we would assign in our courses (e.g., creating a podcast, adding a table to a wordprocessing document, writing conditional statements in ActionScript). Table 3 provides the topic and/or title, producer, and duration of each screencast. Our intention was to look beyond our own collection of self-produced screencasts in order to see whether the overall structure and common format components were generalizable to the larger pool of publicly available screencasts. As with our previous analysis, our overall goal was to decipher the format and corresponding instructional strategies employed in each screencast. 
Table 3

Professionally Produced Screencasts

Screencast topic/title

Producer

Screencast duration

Podcasting using GarageBand

Creating a Podcast

Apple.com

$2: 25$

Setting up the Metronome

Atomic Learning $\quad 1: 42$

Using the Count in Feature

Atomic Learning

1:15

Punching in a Fake

Atomic Learning

$2: 18$

Recording Multi-Take Performances

Atomic Learning $\quad$ 4:03

Recording with Multiple Tracks

Atomic Learning

$1: 20$

Podcasting with GarageBand 3

Lynda.com

$14: 27$

Inserting a Table using Pages

Adding Tables and Charts

Apple.com

$\sim 2: 00$

(no length indicated)

Creating a Table

Atomic Learning

$0: 39$

Selecting Cell Borders

Atomic Learning $\quad 0: 41$

Modifying Cell Borders

Atomic Learning $\quad 0: 34$

Creating Table Headers

Atomic Learning $\quad 0: 42$

About Tables

Lynda.com

$2: 37$

Inserting Tables

Lynda.com

$5: 48$

Creating Conditional Statements with Flash ActionScript 3

Creating a Conditional Statement Pt. 1

Creating a Conditional Statement Pt. 2

Creating a Conditional Statement Pt. 3 $\begin{array}{ll}\text { Atomic Learning } & 2: 34 \\ \text { Atomic Learning } & 3: 28 \\ \text { Atomic Learning } & 2: 07\end{array}$ 


\begin{tabular}{llc} 
Screencast topic/title & Producer & Screencast duration \\
\hline Conditions: Thinking Script & Lynda.com & $7: 38$ \\
Understanding Conditional Statements & Lynda.com & $1: 36$ \\
Writing a Conditional Statement & Lynda.com & $4: 40$ \\
Understanding Conditional Operators & Lynda.com & $1: 37$ \\
Understanding Conditional Operators & Lynda.com & $4: 49$
\end{tabular}

During this phase, we evaluated 25 screencasts in three iterations. The total amount of time for these screencasts was approximately 67 minutes. For each iteration, we concentrated on one particular task and software application. During the first iteration, we evaluated seven screencasts using GarageBand; during the second iteration, we evaluated seven screencasts using Pages; and during the third iteration, we evaluated eight screencasts using Flash Actionscript 3. At the end of each iteration, we again reflected upon the structure of each screencast and identified key common components; we also made notes similar to those in our previous analysis and modified our list of these elements and components in our online document.

\section{Construction of a Screencasting Framework and Corresponding Instructional Strategies}

After analyzing 37screencasts (total length of approximately two hours) within five iterations in the two aforementioned analysis phases, we exhausted our list of common elements of a screencast. At the end of our last iteration, we did not identify additional information related to our analysis. As a result, we constructed a framework that describes common screencast elements (see Figure 1). 
The framework contains two categories: structural elements and instructional strategies. There are three common structural elements: bumpers, screen movement, and narration. There are five instructional strategies: provide overview, describe procedure, present concept, elaborate content, and focus attention. The following subsections define and elaborate upon each category.

\section{Structural Elements}

Structural elements are those that describe the format of a screencast in terms of sectioning, screen recording, and general narrative elements.

\section{Bumpers.}

We observed that screencasts may begin and/or end with a bumper. We borrow the bumper term from radio broadcasts. It refers to a statement of identity at the beginning and/or end of a broadcast. Some screencasts include an initial greeting or bumper (e.g., "Hi, this is your instructor from the Multimedia Production class.") and also have a corresponding ending or bumper (e.g., “This is your instructor from the Multimedia Production class saying goodbye.”).

\section{Screen movement.}

We also observed a difference between static and dynamic movement within screencasts. Some of the examined screencasts followed the cursor. In these screencasts the capture frame moves around the screen, keeping the cursor in the center. In our framework, we refer to this style as dynamic screencast movement. In contrast, other screencasts maintain a constant frame in which the cursor moves within that frame, which we refer to as static screencast movement. Static screencast movement seems to be the default for the majority of screencasts. Dynamic screencast movement seems to occur most often in screencasts developed for advanced users. We hypothesize that designers may feel the need to keep the screen static for beginners because they do not have a well-developed schema for the screen. In contrast, advanced users have an overall mental model of the entire screen and can concentrate on portions of the screen.

\section{Narration.}

Some screencasts' audio commentary is an explicit description of a procedure that coincides with what is displayed on the screen. An example of explicit narration is "click on Edit then click on Select All.” During the narration, the learner sees the mouse clicking on the Edit menu and then the mouse clicking on the Select All option. Other audio commentary is an implicit description of

a procedure. For example, a screencast includes the following narration: "create a new file.” The learner observes the mouse cursor clicking on the File menu and then selecting the New option. A majority of the examined screencasts included a combination of both of these narration formats. 


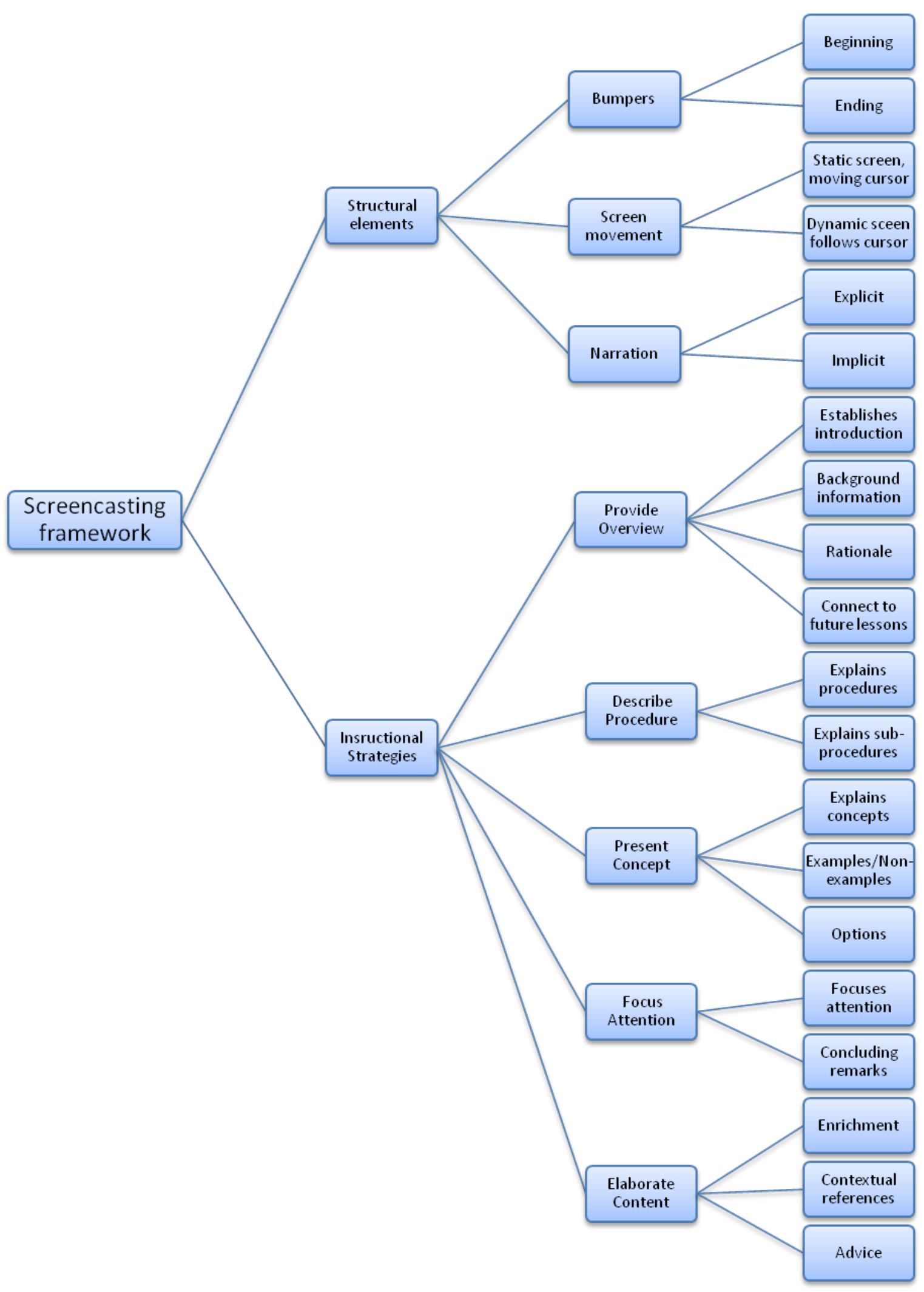

Figure 1. Screencasting framework and corresponding instructional strategies. 


\section{Instructional Strategies}

Five instructional strategies were commonly used in the screencasts evaluated: provide overview, describe procedure, present concept, focus attention, and elaborate content. Although the examined screencasts did not contain instances of every instructional strategy, no screencast contained any other instructional strategy.

\section{Provide overview.}

A common set of instructional strategies concentrated on providing an overview of a particular topic by introducing the topic, giving a rationale for studying the topic, and connecting the lesson topic to future lessons. One goal of this type of strategy is to establish set (a term borrowed from classroom teaching) or to provide an introduction to the particular topic area. Overview strategies provide the necessary background information that learners need in order to understand the context and/or the purpose of the screencasting topic; for example, in the Image Editing screencast, faculty member $\mathrm{C}$ talks about why one would want to resize an image using MS Paint. Sometimes, this overview strategy gave screencast learners the rationale for completing a task or operation; for example, in the Apache Web Server installation screencast, faculty member C talks about why one would install an Apache web server, and in the About Tables screencast, the instructor describes why and how one would use tables in a word-processing file.

A similar instructional strategy occurred at the conclusion of a particular screencast. During this conclusion, an instructor commented on important elements with regard to the particular topic area. These remarks focused learners on key aspects of the screencast. In the About Tables screencast, the instructor informed the learners about the upcoming Tables screencasts and how this information would be connected. In the Image Size and Resolution screencast, faculty member B summarized what the learners learned in the particular screencast and commented that they had changed the image size and resolution in the particular screencast. Highlighting key elements enabled learners to concentrate on essential steps within a screencast.

\section{Describe procedure.}

The focus on providing procedural knowledge is evident in screencasts. There is a direct correspondence with Udell's (2005) screencasting definition (i.e., "digitally recorded playback of computer screen output which often contains audio narration") and the demonstration of routines and tasks. Most of the screencasts examined during our investigation demonstrated a procedure and thus included this instructional strategy. We also found that an individual screencast sometimes included one or more sub-procedures. For example, in the Adding a Frame Label screencast, faculty member A demonstrated the procedure for copying and pasting a menu button within Flash in order to demonstrate how to create a frame label. In the screencast Dreamweaver Basics Part 2, faculty member B demonstrated multiple page-modification procedures, including how to insert an image into an HTML page and how to change the background color. 


\section{Present concept.}

In addition to imparting procedural knowledge within screencasts, we found that several screencasts offered an explanation of a specific concept related to the screencast topic (e.g., differences between a JPEG file and a PNG file, object-oriented programming, the PHP programming language). To explain a concept, some of the screencasts used a common example/non-example instructional strategy to demonstrate similarities and differences. In the Adding a Link - Basic screencast, faculty member A demonstrated what happens if one does not select the correct shape when creating a link within a Flash module. A similar instructional strategy to illustrate a concept was to describe options available in completing a procedure. For instance, in the Recording Multi-Take Performances screencast, the instructor informs learners that one can use cycle recording as a suitable alternative. Or in the Creating a Table screencast, learners are told that one can change the look of a table by changing its shading and opacity. This combination of describing a concept related to the procedure along with demonstrating the procedure itself appeared to be an effective instructional strategy.

\section{Focus attention.}

Attention focusing is another common instructional strategy employed. The narration and/or cursor location direct learners' attention to a particular component on the screen or to a certain part of an overall procedure. For example, in the InDesign Basics screencast, after demonstrating selecting an image in an InDesign file, faculty member B's narration informs learners that they can observe information about a selected item; attention is focused on the selection by demonstrating selecting an item and using the cursor to circle the selection's information. In the Adding a Link - Basics screencast, faculty member A directed learners' attention to the stroke color icon and informed them that there needs to be a red line in this icon in order to create an invisible button.

\section{Elaborate content.}

In our analyses, we found that screencasting instructors elaborated beyond the topic with regard to a particular procedure, concept, or other aspect of the screencast. This instructional strategy facilitates opportunities to enrich learners' understanding and to encourage learners to consider other aspects of the process or concept associated with the screencast's subject-matter. By providing these additional details, the instructor makes contextual references to similar instructional settings that are relevant to the screencast content. For example, both faculty member A and faculty member B describe prior coursework and assignments in relation to the particular activity in their respective Adding a Link - Advanced, and Dreamweaver Basics Part 2 screencasts.

Another example of an elaboration strategy involves the instructor offering advice about how best to use a particular tool or technique described in the screencast. In the Writing a Conditional Statement screencast, the instructor recommends that learners be consistent in writing 
Actionscript 3 code because the code for an action may be written in a variety of ways. In the Image Size and Resolution screencast, faculty member B explains to learners how to locate a web-friendly image prior to inserting the image into a Dreamweaver file. This elaboration instructional strategy enhances the screencast and further strengthens learners' overall comprehension of the topic.

\section{Discussion}

There is no doubt that screencasts are becoming important instructional tools for online learning environments. Our study provides information on the structure and instructional strategies currently in use for screencasts, and it provides a framework for evaluating screencast instructional content. See the Appendix for a checklist that is based upon the screencasting framework in use in this evaluation process. We encourage this evaluation process both to determine the instructional effectiveness of a finished screencast and to serve as a pre-production checklist for screencasting.

This framework and corresponding checklist address one of our primary research questions. That is, how can we understand the key components of a screencast? Though this framework and corresponding checklist is without question a result of our initial inquiry, we anticipate continuing research that will lead to improvements. Establishing this starting place is a vital step in comprehending screencasts as instructional tools.

It should be noted that screencasting as an instructional strategy may be viewed as a modern descendent of instructional film and video. The research and recommendations borne out of endeavors such as the visual instruction movement of the 1920s, the Office of Education Training Films in the 1940s, the Instructional Film Research Program in the 1950s, and the DenverStanford Project of the 1960s, to name but a few, may be applied to instructional screencasting, particularly in terms of identifying key structural components. See Saettler (1990) for a more complete history and discussion of the impact of visual instruction and educational film and video.

Prior to this study, we operated under the assumption that screencasts were a compilation of procedures only. We realize now that this is not true. By identifying numerous instructional strategies besides the familiar description of a procedure, we recognize the need to consider how the full spectrum of instructional strategies (e.g., elaboration, attention focusing, concept attainment) can be employed in screencasting. Understanding the surprisingly complex nature of screencasts enables producers to make best use of a variety of instructional strategies and provides schema for consumers that help them to understand fully screencasting's instructional potential and the value of specific screencasts.

It also appears that faculty members have unique screencasting teaching styles. After examining a couple of screencasts by one individual, we could anticipate how a screencast by that individual would be structured and developed prior to observing it. 


\section{Recommendations for Further Research}

More research on the connection between one's overall teaching philosophy, overall online course development, and screencast development should take place. This could lend insight into the overall development of screencasts and their effect on online course delivery.

Similarly, future research on how screencast learners' responses to individual screencasts relate to their respective mental models is needed. Observing learners' reactions to screencasts that make use of different instructional strategies would lend additional insight. In a future thinkaloud protocol study, these learners can offer additional information on the best ways to create effective screencasts and also possibly provide additional effective instructional strategies.

In the future, we hope to see more research addressing questions regarding specific and effective instructional strategies for each of the areas of our framework: for example, what elaboration instructional strategies are best used in screencasting or what are the best techniques for teaching conceptual knowledge in a screencast? Similarly, because there is a strong connection between video-based screencasts and educational television, a re-examination of educational television research conducted from the 1970s through the 1990s should take place. Revisiting this literature would help identify and study the effect of these broadcast variables (e.g., bumpers) within current screencasts. This would likely provide valuable information for instructional designers and screencast producers.

\section{Limitations}

While we were able to examine a number of screencasts from a variety of producers, ranging from our self-produced efforts to those that were professionally produced, we recognize that this sample by no means represents the full population of screencasts produced and made available to either the general public or students in specific courses. Additionally, we did not evaluate screencasts that recorded face-to-face instruction. Therefore it is possible that we were unable to observe additional structural elements or instructional strategies that may have been employed by those producers whose efforts are not included in this study. Our framework and checklist is comprehensive for the screencasts we observed but may need updating to include more structural elements and instructional strategies.

Furthermore, while three observers helped control reliability of examination, we recognize the possibility that other observers may identify the use of structural elements and instructional strategies that we overlooked. 


\section{Conclusion}

We hope the findings from our current investigation will help screencast developers and online instructors become more aware of the structure of screencasts and of specific instructional strategies employed in screencasting. Our framework and checklist provide a reference for both evaluation and production. We encourage screencast development that makes informed choices regarding the overall structure and the instructional strategies employed in screencasting. 


\section{References}

Betty, P. (2008). Creation, management, and assessment of library screencasts: The Regis Libraries animated tutorials project. Journal of Library Administration, 48(3/4), 295-315.

Ellington, A. J., \& Hardin, J. R. (2008). The use of video tutorials in a mathematical modeling course. Mathematics and Computer Education, 42(2), 109-117.

Hartsell, T. \& Yuen, S. (2006). Video streaming in online learning. AACE Journal, 14(1), 31-43.

Heron, J. (1996). Co-operative inquiry: Research into the human condition. London: Sage Publications.

Jenkins-Brown, A.R. (2008). Casting a wider net: Using screencast tutorials to advance library involvement in supporting research practices. Presented at the Joint Meeting of The Geological Society of America, Soil Science Society of America, American Society of Agronomy, Crop Science Society of America, Gulf Coast Association of Geological Societies with the Gulf Coast Section of SEPM. Houston, TX.

Lee, M. J. W., Pradhan, S., \& Dalgarno, B. (2008). The effectiveness of screencasts and cognitive tools as scaffolding for novice object-oriented programmers. Journal of Information Technology Education, 7, 61-80.

Mayer, R. (2001). Multimedia learning. New York: Cambridge University Press.

Paivio, A. (1986). Mental representations: A dual coding approach. Oxford, UK: Oxford University Press.

Pang, K. (2009). Video-driven multimedia, web-based training in the corporate sector: Pedagogical equivalence and component effectiveness. The International Review of Research in Open and Distance Learning, 10(3). Retrieved from http://www.irrodl.org/index.php/irrodl/article/view/629.

Peterson, E. (2007). Incorporating screencasts in online teaching. The International Review of Research in Open and Distance Learning, 8(3). Retrieved from http://www.irrodl.org/index.php/irrodl/article/viewArticle/495/935.

Phillips, J. M., \& Billings, D. M. (2007). Using webcasts for continuing education in nursing. Journal of Continuing Education in Nursing, 38(4), 152-153.

Reason, P., \& Riley, S. (2008). Co-operative inquiry: An action research practice. In J.A. Smith (Ed.), Qualitative psychology: A practical guide to research methods (2nd ed.). London: Sage Publications. 
Saettler, P. (1990). The evolution of American educational technology. Englewood, CO: Libraries Unlimited.

Soloman, H. (n.d.). Cognitive load theory (J. Sweller). The Theory into Practice Database. Retrieved from http://tip.psychology.org/sweller.html.

Sweller, J. (1988). Cognitive load during problem solving: Effects on learning. Cognitive Science, 12(2), 257-285.

Traphagan, T., Kucsera, J. V., \& Kishi, K. (2010). Impact of class lecture webcasting on attendance and learning. Educational Technology Research \& Development, 58(1), 1937.

Udell, J. (2005). What is screencasting? Retrieved from http://digitalmedia.oreilly.com/pub/a/oreilly/digitalmedia/2005/11/16/what-isscreencasting.html?page=2\#heading2.

Van Laarhoven, T., Munk, D. D., Zurita, L. M., Lynch, K., Zurita, B., Smith, T., \& Chandler, L. (2008). The effectiveness of video tutorials for teaching preservice educators to use assistive technologies. Journal of Special Education Technology, 23(4), 31-45.

Wouters, P., Paas, F. \& van Merrienboer, J.G. (2008). How to optimize learning from animated models: A review of guidelines based on cognitive load. Review of Educational Research 78(3), 645-675. 


\section{Appendix}

\section{Screencast Observation Checklist}

\begin{tabular}{|l|l|}
\hline File Name & \\
\hline Producer & \\
\hline Observer \& Date & \\
\hline Duration & \\
\hline
\end{tabular}

\begin{tabular}{|l|l|}
\hline \multicolumn{1}{|c|}{ Structural elements } & Comments \\
\hline$\square$ Beginning Bumper & \\
\hline$\square$ Ending Bumper & \\
\hline$\square$ Screencast movement (Static or Dynamic) & \\
\hline$\square$ Narration (Explicit or Implicit) & \\
\hline
\end{tabular}

\begin{tabular}{|l|l|}
\hline Instructional Strategies Employed & Comments \\
\hline Overview & \\
$\square$ Establishes Set (Introduction) & \\
$\square$ Provides Background Information & \\
$\square$ Provides Rationale & \\
\hline Future Lessons & \\
Procedural knowledge & \\
$\square$ Explains Procedure & \\
$\square$ Explains Sub Procedure(s) & \\
Conceptual knowledge & \\
$\square$ Explains Concepts & \\
$\square$ Provides Examples/Non-Examples & \\
$\square$ Explains Options & \\
\hline Attention focusing & \\
$\square$ Focuses Attention & \\
\hline Provides Concluding Remarks & \\
Elaboration & \\
$\square$ Provides Enrichment & \\
$\square$ Oakes Contextual References & \\
\hline
\end{tabular}




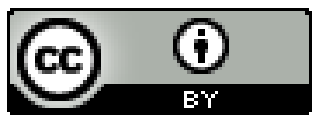

